\title{
Shallow structure of part of northwestern Iberia from short-period Rayleigh-wave observations
}

\author{
J. Sarrate ${ }^{\text {a }}$, J.A. Canas ${ }^{\text {b }}$, L. Pujades ${ }^{\text {b }}$, J. Badal ${ }^{\text {c }}$, V. Corchete ${ }^{\text {c }}$ and G. Payo ${ }^{\text {d }}$ \\ a Dep. de Matemàtica Aplicada III, Universitat Politècnica de Catalunya, Barcelona, Spain \\ ${ }^{b}$ Dep. de Enginyería del Terreny i Cartogràfica, Universitat Politècnica de Catalunya, Barcelona, Spain \\ 'Dep. de Física Teórica (Geofisica), Universidad de Zaragoza, Zaragoza, Spain \\ ${ }^{d}$ Observatorio Geofisico Central de Toledo, I.G.N, P.O. Box 446, 45071 Toledo, Spain
}

(Received January 28, 1991; revised version accepted October 22, 1991)

\begin{abstract}
Sarrate, J., Canas, J.A., Pujades, L., Badal, J., Corchete, V. and Payo, G., 1993. Shallow structure of part of northwestern Iberia from short-period Rayleigh-wave observations. In: J. Badal, J. Gallart and H. Paulssen (Editors), Seismic Studies of the Iberian Peninsula. Tectonophysics, 221: 95105.
\end{abstract}

\begin{abstract}
Propagation of $\mathbf{0 . 2 - 2 . 5} \mathrm{s}$ short-period Rayleigh-waves across a part of northwestern Iberia is investigated. Analysis of a seismic profile line with recorded seismograms up to distances of $70 \mathrm{~km}$ from the shot-point, provides group-velocities and attenuation coefficients of the fundamental mode. First higher-mode group-velocity has been obtained for only one of the studied cases. The studied region has been divided into two subregions, the northwestern and the southeastern side from the shot-point. Inversion procedures applied to the velocity and attenuation data yield the shear velocity and the $Q_{\beta}^{-1}$ models up to a depth of about $1.5 \mathrm{~km}$ for the NW, and 2.4 for the SE side. From the shear-wave obtained models corresponding to the NW and to the SE sides, it is possible to infer the existence of some degree of lateral variation of S velocity. The NW side presents velocities varying between $1.8 \mathrm{~km} \cdot \mathrm{s}^{-1}$ (at the surface) and $3.3 \mathrm{~km} \cdot \mathrm{s}^{-1}$ (at $1.2 \mathrm{~km}$ depth). The velocities in the SE model, for the same depths, are 2.2 and $3.4 \mathrm{~km} \cdot \mathrm{s}^{-1}$, respectively. Using only the fist six traces of the SE side, it is possible to infer a low-velocity region located between $0.4 \mathrm{~km}$ and $0.7 \mathrm{~km}$ depth. It seems that the velocities are higher in the complex geological region of the SE side than in the NW one, which is in agreement with $\mathrm{P}$ velocity models found by others. From the tentative anelastic attenuation coefficients, $Q_{\beta}^{-1}$ models have been inferred for both sides of the seismic refraction profile. Although the obtained $\mathrm{Q}_{\beta}^{-1}$ models are somehow different in shape, the maximum $Q_{\beta}^{-1}$ value is about 0.05 in both cases.
\end{abstract}

\section{Introduction}

Interpretations of seismic refraction profiles are usually made in terms of travel time data (e.g., Córdoba et al., 1987). Amplitudes are useful for theoretically modelling the observed seismic traces (e.g., Fuchs and Müller, 1971). To investigate the velocity structure of the crust and mantle, the seismic refraction method is the best way. Short-period surface-waves are, however, useful to provide the features of the top most crustal

Correspondencè to: Dr. J. Sarrate, Dep. de Matemàtica Aplicada III, Universitat Politècnica de Catalunya, 08028 Barcelona, Spain. layers. Some recent studies in other parts of the world (e.g., Macbeth and Burton, 1986; Mokhtar et al., 1988) seem to indicate that this may be an interesting technique to determine shallow structure in crustal regions. Velocity and anelasticity distribution can be obtained using inversion methods applied to the observed surface-wave data (e.g., Canas et al., 1988; Badal et al., 1990). Techniques originally developed to determine deep structure can be applied in the same manner to determine shallow structure (Russell, 1987). Several workers (e.g., Herrmann, 1973; Mokhtar et al., 1988) have presented and applied techniques to isolate group-velocities and attenuation coefficients of the fundamental and higher modes. 
The main goals of this study are:

(1) To determine fundamental-mode groupvelocities and attenuation coefficients using short-period Rayleigh-waves observed in seismic profile traces corresponding to a region in the northwestern part of Iberia.

(2) To invert the short-period data to infer shear velocity and $Q_{\beta}$ models for the region under study.

As far as we know, this is the first time that a work with these characteristics is carried out in the Iberian Peninsula. As the applied methodology and the obtained results are satisfactory, the scheme of this study will be applied in a near future to the short-period surface-waves observed in the seismic profile records during the ILIHA Project (late 80 's), to refine the determined velocity structure and to determine the unknown anelastic behavior of the shallow crust of Iberia.

\section{Data}

The northwestern part of the Iberian Peninsula is an area where the Alpine orogeny has not caused important changes. In 1982, a seismic refraction survey was carried out in the region of this study (Córdoba, 1988). Several seismic refraction profile lines were made. Only one of the shot-points generated clear surface-waves. Figure 1 shows the shot-point and the profile line. The $S$ velocity simplified initial model (three layers over a half-space) for the inversion procedure applied in this study, is based on the compressional velocity model of Córdoba (1988), determined for a wide region in northwestern Iberia including the area of this study. The $\mathbf{S}$ velocity starting model has been conveniently modified, in accordance with the observed Rayleigh-wave velocity data, to perform the inversion procedure properly.

All traces were recorded with $2 \mathrm{~Hz}$ MARK-LA3D geophones with the longitudinal direction oriented to the shot-point. The Rayleigh-wave vertical component records have been used for the present study. The traces were digitized at irregular intervals; a posterior linear interpolation provided a constant time interval of $0.02-0.08 \mathrm{~s}$, depending on the frequency content of the seismograms. All the traces were corrected for in-
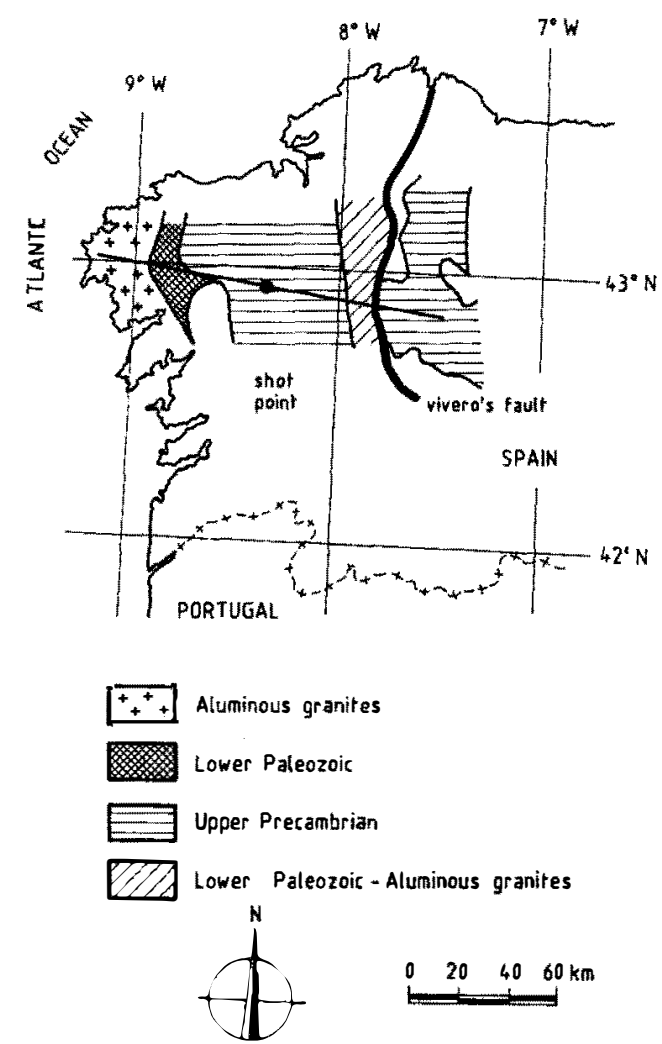

Fig. 1. Northwestern part of the Iberian Peninsula. Schematic representation of the geological structures (modify from Matte, 1983). The dot indicates the shot-point location, and the straight line the seismic profile used.

strumental response. Figure 2 shows the recorded seismic traces.

\section{Methodology}

The procedure to obtain the shear velocity and the $Q_{\beta}^{-1}$ models is the following. First, groupvelocities and attenuation coefficients, as a function of the period, are determined. Second, generalized inversion theory is applied to the velocity and attenuation data to obtain the shallow models.

The determination of the group-velocities and the anelastic attenuation coefficients are based on the multiple filter technique (Dziewonski et al., 1969; Herrmann, 1973). The far field ground motion displacement, due to multimode surface- 


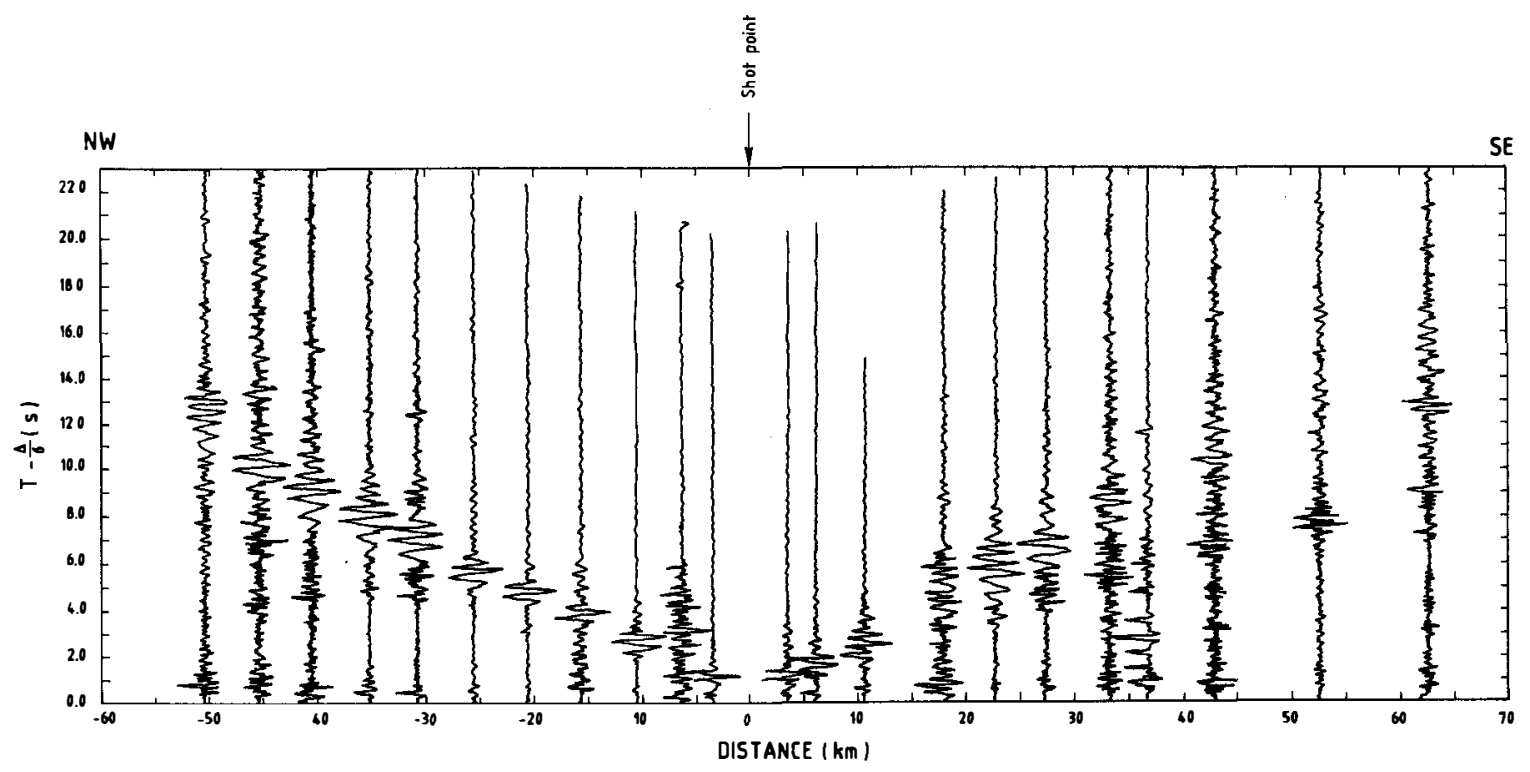

Fig. 2. Recorded seismic traces from the seismic profile in Figure 1.

wave propagation, is described by Herrmann (1973) as:

$$
f(r, t)=\frac{1}{2 \pi} \int_{-\infty}^{+\infty} \sum_{i=0}^{N} A_{i}(r, \omega) \mathrm{e}^{i(\omega t-k j r)} \mathrm{d} \omega
$$

where $N+1$ is the number of modes present in the surface-wave, $A_{i}$ is the $i$ th mode amplitude, $k_{i}$ is the wavenumber for the $i$ th mode, and $\omega$ is the angular frequency. The Fourier transform of the signal is then multiplied by a narrow band-pass Gaussian filter, centered at the frequency of interest, providing arrival times and amplitudes from which group-velocities can be determined. Mohktar et al. (1988) showed that isolation of the velocity and amplitude data corresponding to the fundamental and the first higher mode, can be performed using linear regression analysis applied to the set of group-velocities and spectral amplitudes, as a function of the frequencies, obtained by the multiple filtering.

To compute the attenuation coefficients, $\gamma$, we have used the following relationship between the observed amplitude spectra at distance $r$ and the corresponding one at the source:

$$
A_{r}(\omega)=A_{0} G(r) \text { e }^{\gamma(\omega) r}
$$

$A_{0}$ is the amplitude at the source and $G(r)$ is the geometrical spreading factor. Application of Eq.
(2) to any two observed spectral amplitudes at distances $r_{1}$ and $r_{2}$ from the source, supposing the source and the observation points on the same straight line, avoids the effect of the $A_{0}$ term and, therefore, attenuation coefficients can be computed from the observed spectral amplitude decay with distance.

\section{Inversion theory and surface-wave application}

A general formulation for linear inversion theory can be found in Wiggins (1972). The problem under study is a linearizable one; therefore, we have adopted the following approach:

$\boldsymbol{y}=\boldsymbol{A x}$

where $\boldsymbol{x}$ is the model to be determined, $\boldsymbol{y}$ is the data vector containing the observation data and $\boldsymbol{A}$ is the matrix that relates the parameters of the model with the observations. Considering that the data are contaminated by noise, Eq. (3) can be written as:

$\boldsymbol{y}=\boldsymbol{A x}+\boldsymbol{e}$

The problem is solved by searching the minimum for the vector $\boldsymbol{e}$ (e.g., Menke, 1989), considering normalized unknowns and data. In this study the data vector is the obtained group-velocities, $U_{i}(\omega)$, or the obtained attenuation coefficients, $\gamma_{i}(\omega)$. 
The models to be determined are the shear-wave velocity, $\beta$, and the $Q_{\beta}^{-1}$ distributions as a function of depth.

Shear-wave velocity has been selected as the independent variable to perform the inversion because dispersion is more sensitive to shear velocity than to compressional velocity or density (e.g., Russell, 1987). Expanding the group-velocity, considering a starting model, $\beta^{*}$, Eq. (4) can be written as:

$\delta U=A \delta \beta+e$

where $\delta \beta_{i}=U_{i}^{\text {ob }}-U_{i}\left(\beta^{o}\right)$ and $U_{i}^{\text {ob }}$ is the observed group-velocity. An iterative procedure, applying a first-order difference technique, solves Eq. (5) (Twomey, 1977). Partial derivatives in Eq. (5) are computed applying the procedure of Rodi et al. (1975).

To compute $Q_{\beta}^{-1}$ models, the inverse problem is formulated from the attenuation data. To construct the matrix formulation (4), we use the formulation of Mitchell (1975):

$\gamma(\omega)=\frac{\pi}{T}\left(\sum_{j}^{n} \frac{\alpha_{j}}{C^{2}} Q_{\alpha_{j}}^{-1} \frac{\partial C}{\partial \alpha_{j}}+\sum_{j} \frac{\beta_{j}}{C^{2}} Q_{\beta_{j}}^{-1} \frac{\partial C}{\partial \beta_{j}}\right)$

where $\alpha$ is the compressional velocity, $n$ is the number of layers, and $T$ is the period. Assuming that there are no losses in pure compression, and following Anderson et al. (1965), the compressional wave factor, $Q_{\alpha}$, can be related to the shear one, $Q_{\beta}$, as:

$Q_{\beta}^{-1}=\frac{3}{4}\left(\frac{\alpha}{\beta}\right)^{2} Q_{\alpha}^{-1}$

Using Eqs. (6) and (7), the attenuation coefficients can be related to $Q_{\beta}^{-1}$ as:

$\gamma(\omega)=\frac{\pi}{T} \sum_{j}^{n}\left[\left(\frac{4}{3}\left(\frac{\beta_{j}}{\alpha_{j}}\right)^{2} \frac{\alpha_{j}}{C^{2}} \frac{\partial C}{\partial \alpha_{j}}\right)\right] Q_{\beta_{j}}^{-1}$

This equation can be easely expressed in the matrix notation given by Eq. (4). Standard errors for the shear and anelastic models are determined using the expression determined by Mitchell (1976).

The initial model for the shear velocity inversion procedure is, as mentioned before, a simpli- fied one formed by three horizontal layers over a half-space. This model will be shown together with the final $\mathrm{S}$ velocity distributions determined in this study.

Because $Q_{\beta}$ values are not known for the region under study, we have assumed the following starting model: $Q_{\beta}^{-1}=1$ for all depths. We have tried several different starting models, with one, two and three layers, and with different values of $Q_{\beta}^{-1}$ for each layer, but the results were practically the same. Thus, we have selected the easiest model to initiate the inversion.

\section{Results}

\section{Velocity results}

The methodology explained above has been applied to all seismic traces shown in Figure 2. In addition, the first six traces in the SE direction have been analyzed separately because in this direction the surface-waves vanish at about $35 \mathrm{~km}$ from the shot-point.

Fundamental-mode Rayleigh-wave groupvelocities have been determined applying the multiple filter technique (Dziewonski et al., 1969; Herrmann, 1973), modified by the extension of Barker (1988), to the traces in the NW and SE direction. Fundamental and first higher-mode group-velocities have been obtained for the first six traces in the SE direction. Normalized energy plots of the group-velocity as a function of frequency were drawn at different levels with respect to the maximum normalized value of the energy, taken equal to 1 (Fig. 3). The average results show that, for the NW traces (Fig. 4), the fundamental-mode group-velocity dipersion lies between $1.7 \mathrm{~km} \cdot \mathrm{s}^{-1}$ at periods about $0.2 \mathrm{~s}$ and $2.0 \mathrm{~km} \cdot \mathrm{s}^{-1}$ at periods about $0.9 \mathrm{~s}$. For the SE traces the fundamental group-velocities are somewhat higher, close to $2.0 \mathrm{~km} \cdot \mathrm{s}-1$ at $0.2 \mathrm{~s}$ and $2.75 \mathrm{~km} \cdot \mathrm{s}^{-1}$ at $2.5 \mathrm{~s}$. (Fig. 5). Figure 6 presents the average group-velocities of the fundamental and first higher modes of the Rayleigh-wave vertical component corresponding to the first six traces of the SE side of the profile in Figure 1. For the fundamental mode, the group-velocities range from about $1.8 \mathrm{~km} \cdot \mathrm{s}^{1}$ at 


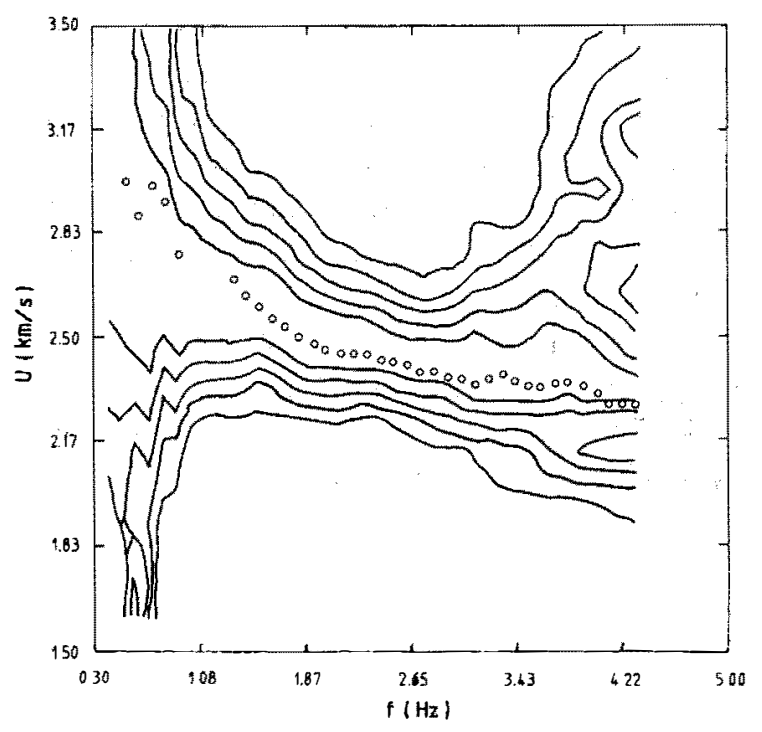

Fig. 3. Example of energy diagram for the fundamental-mode Rayleigh-wave vertical component of one of the traces corre sponding to the NW side of the profile in Figure 1. The energy contours vary between $90 \%$, close to the maximum energy (circles, 100\%), and 50\%. The maximum values define the group-velocity dispersion curve.

$0.2, \mathrm{~s}$ to about $2.7 \mathrm{~km} \cdot \mathrm{s}^{1}$ at $2.5 \mathrm{~s}$. For the first higher mode, the velocities vary between 2.35 $\mathrm{km} \cdot \mathrm{s}^{-1}$ at $0.2 \mathrm{~s}$, to $2.85 \mathrm{~km} \cdot \mathrm{s}^{-1}$ at $0.4 \mathrm{~s}$.

Figures $7 \mathrm{a}, 8 \mathrm{a}$ and $9 \mathrm{a}$ present the shear velocity models obtained by inversion, together with their corresponding resolving kernels. Figures $7 \mathrm{~b}$, $8 \mathrm{~b}$ and $9 \mathrm{~b}$ present the matching between the observed velocity data and the theoretical ones

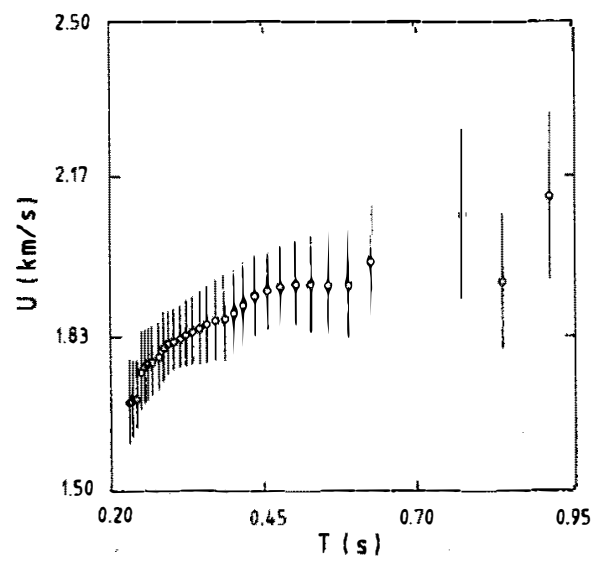

Fig. 4. Average fundamental-mode Rayleigh-wave group velocity for the NW side. Vertical bars indicate standard deviations.

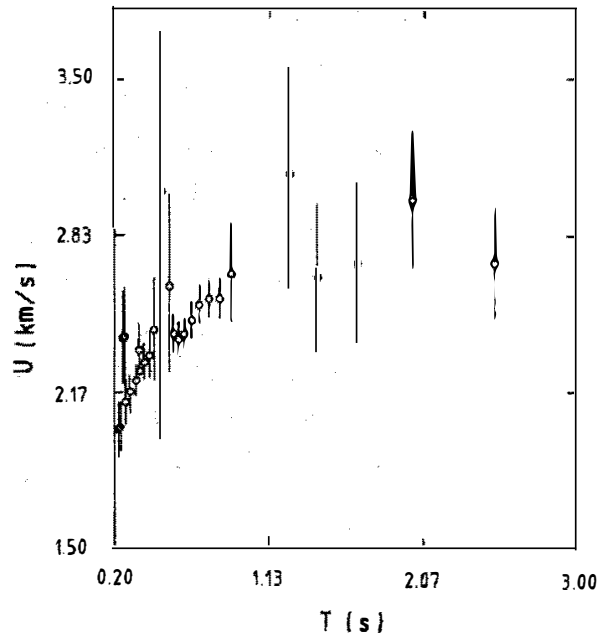

Fig. 5. Average fundamental-mode Rayleigh-wave group velocity for the SE side. Vertical bars indicate standard deviations.

obtained from the models in Figures 7a-9a. Figures $7 \mathrm{a}$ and $8 \mathrm{a}$ present the results for the NW and SE directions respectively, using the fundamental-mode group-velocities only; they indicate that the obtained models explain the observed data well, although the obtained resolving kernels indicate poor resolution for depths larger than about $0.5 \mathrm{~km}$.

Figure 9a presents the inversion results for the first six traces in the SE direction (Fig. 2). In this

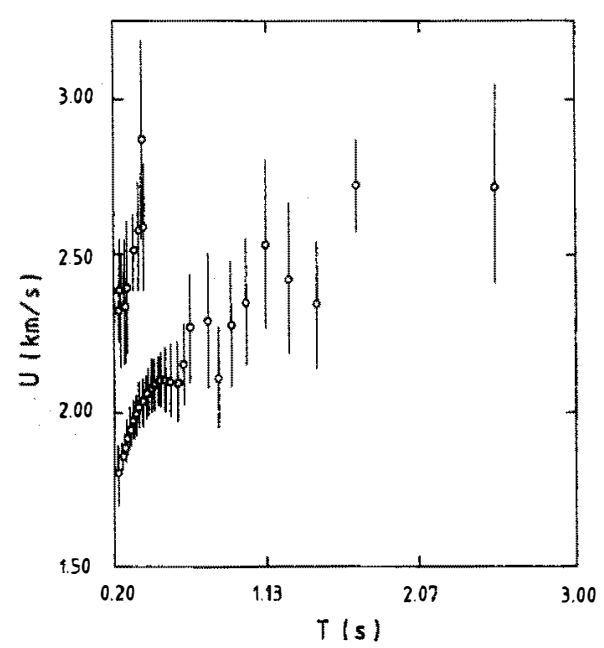

Fig. 6. Average fundamental- and first higher-mode Rayleigh-wave group-velocities determined for the first six traces of the SE side. Vertical bars indicate standar deviations. 
case the fundamental and the first higher-mode group-velocities have been used in the inversion procedure. Figure $9 \mathrm{~b}$ indicates that the obtained model fits both modes properly. The resolving kernels in this case are somewhat better than the ones in Figures $7 \mathrm{a}$ and $8 \mathrm{a}$. It seems that the introduction of the first higher mode in the inversion procedure tends to improve them.

In general, the obtained shear velocity distribution seems to be lower than the $S$ velocity deduced from the model of Córdoba (relation:
$\left.v_{\mathrm{P}} \approx 1.7 v_{\mathrm{S}}\right)$. This fact may be due to the presence of sediments, which usually tends to slow the S-waves more than the P-waves. Moreover, the model of Córdoba (1988) gives average $P$ velocity values for the upper $5 \mathrm{~km}$, and the results of this study correspond to the upper $1 \mathrm{~km}$ or 2 $\mathrm{km}$ of the crust.

Comparison between the NW and SE shear velocity models indicates the following. The model for the NW traces is determined up to a depth of about $1.2 \mathrm{~km}$, while the model for the SE traces is
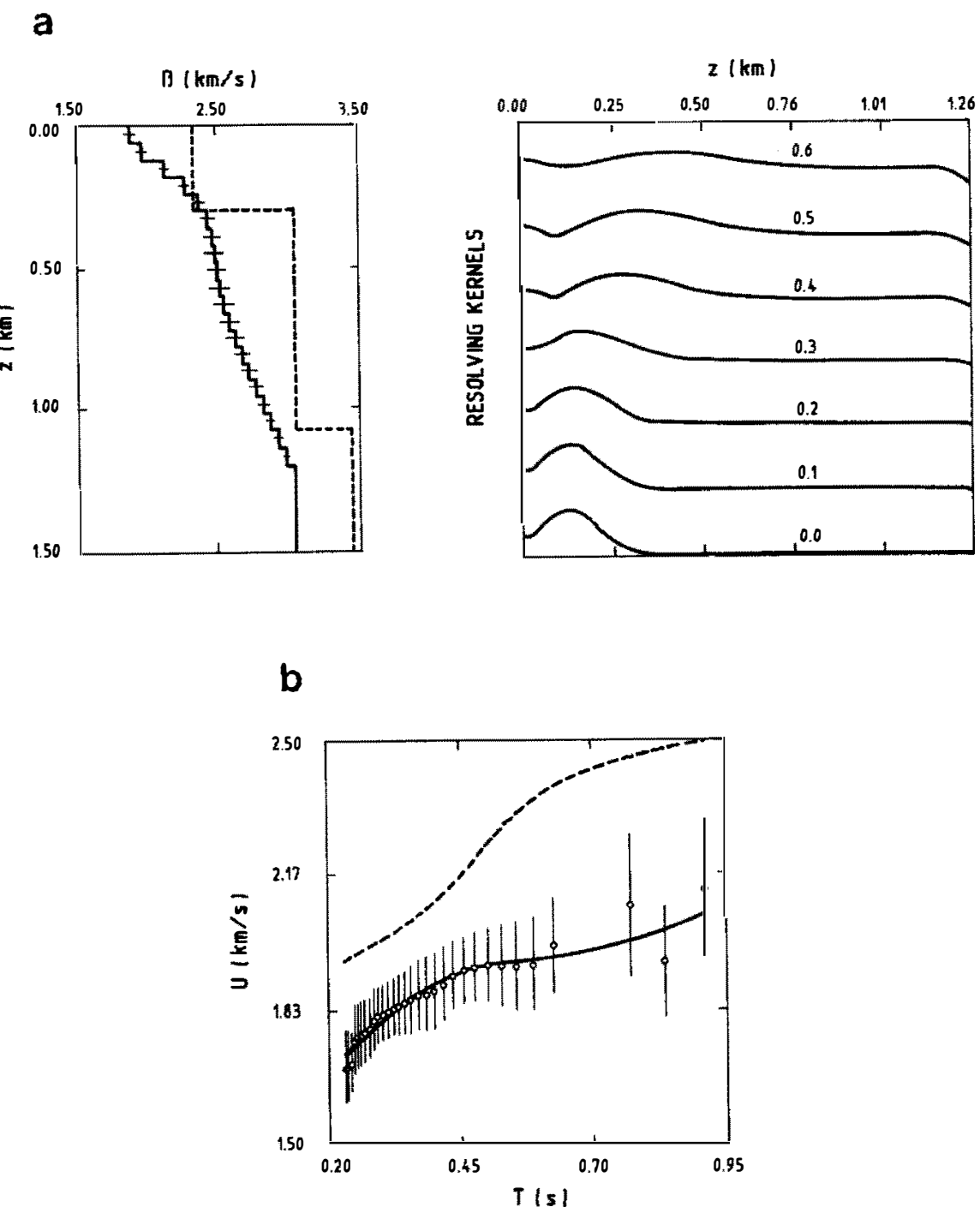

Fig. 7. (a) Shear velocity model corresponding to the NW side of the profile in Figure 1, together with the resolving kernels calculated at several reference depths. The model with three layers indicates the starting model for the inversion procedure. (b) Observed (circles) and theoretical (solid line) Rayleigh-wave dispersion. Vertical bars indicate standard deviations of the velocity data. The dashed line indicates the theoretical group velocity determined from the shear starting model. 
determined up to $2 \mathrm{~km}$. The shear velocity models obtained for the NW and the SE directions are qualitatively similar, both of them showing low velocities in the first $200 \mathrm{~m}$, followed by a gradual increase of velocity with depth until the half-space is reached. For the NW side, the shear velocity varies between a value of $1.8 \mathrm{~km} \cdot \mathrm{s}^{-1}$ at the surface and a value about $3.3 \mathrm{~km} \cdot \mathrm{s}^{-1}$ at a depth of $1.2 \mathrm{~km}$. The model for the $\mathrm{SE}$ region presents higher velocities than the corresponding model for the NE part, being for the same depths mentioned before $2.2 \mathrm{~km} \cdot \mathrm{s}^{-1}$ and $3.4 \mathrm{~km} \cdot \mathrm{s}^{-1}$, respectively. This fact could indicate that lateral variation in the shallow shear velocity structure may exist in the region under study.

When the inversion procedure is applied to the first six SE traces, where the fundamental and the first higher modes are used, a quick change in velocity is observed in the first $0.3 \mathrm{~km}$, with velocity values varying between 2.1 and 2.75 $\mathrm{km} \cdot \mathrm{s}^{-1}$. The difference between this model (Fig. 9a) and the model found when all the traces are considered (Fig. 8a) is that, in the model of Figure 9a, a low-velocity layer appears, between

\section{a}
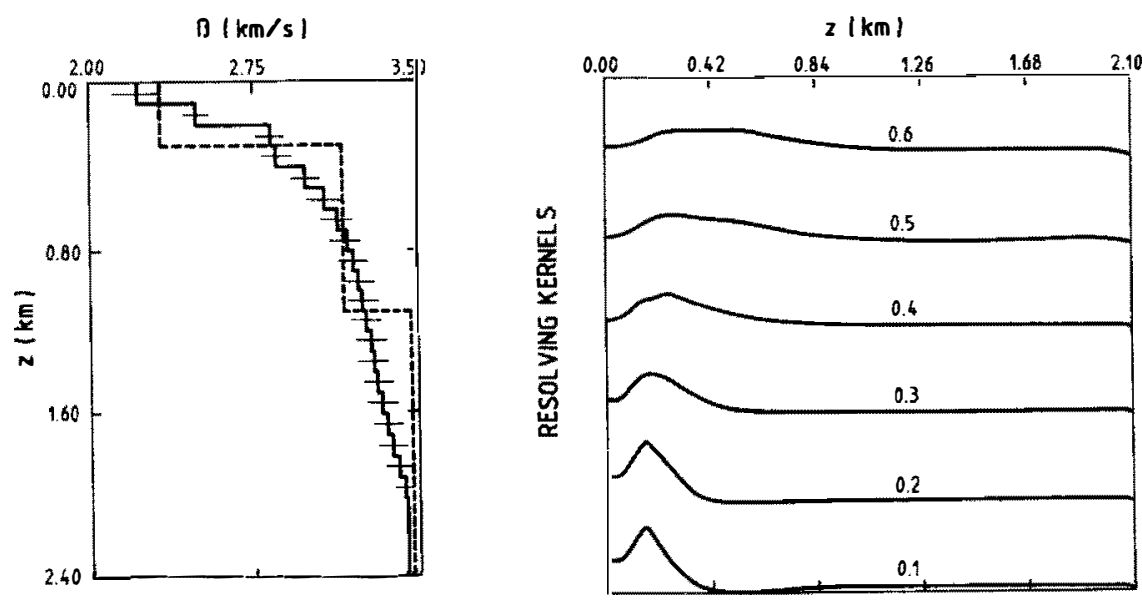

b

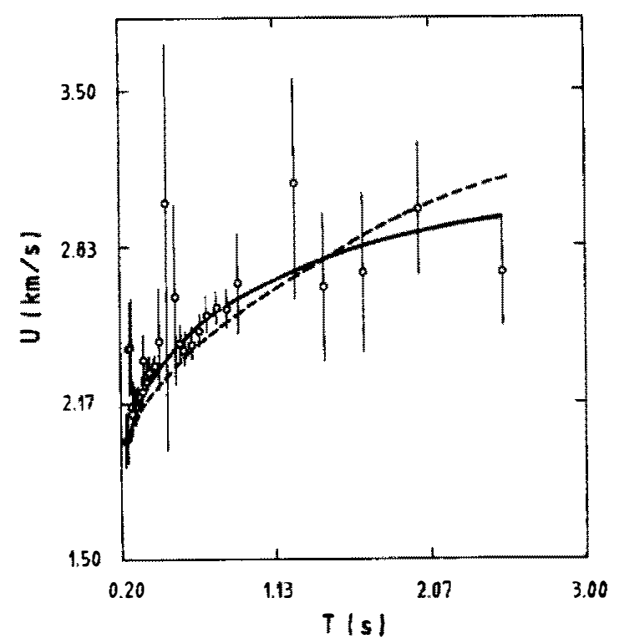

Fig. 8. Same as Figure 7, referred to the SE side of the profile in Figure 1. 
0.4 and $0.7 \mathrm{~km}$ depth, that is not present in the model of Figure 8a. The differences observed between the models in Figures $8 \mathrm{a}$ and 9a may be due to the fact that the model in Figure $8 \mathrm{a}$ has been determined using only fundamental-mode group-velocity data, while the model in Figure 9a has been determined using fundamental and first higher modes. Therefore, the determined model in Figure $9 \mathrm{a}$ is better constrained than the corre- sponding one in Figure 8a. Another way to explain the observed differences is considering the existence of a low-velocity channel only in the first half of the SE direction. More data will be necessary to determine which is the appropiate model for this direction.

The seismic refraction profile was carried out in a very complex geological area (Fig. 1). The geological configuration of the $\mathrm{NW}$ side of the
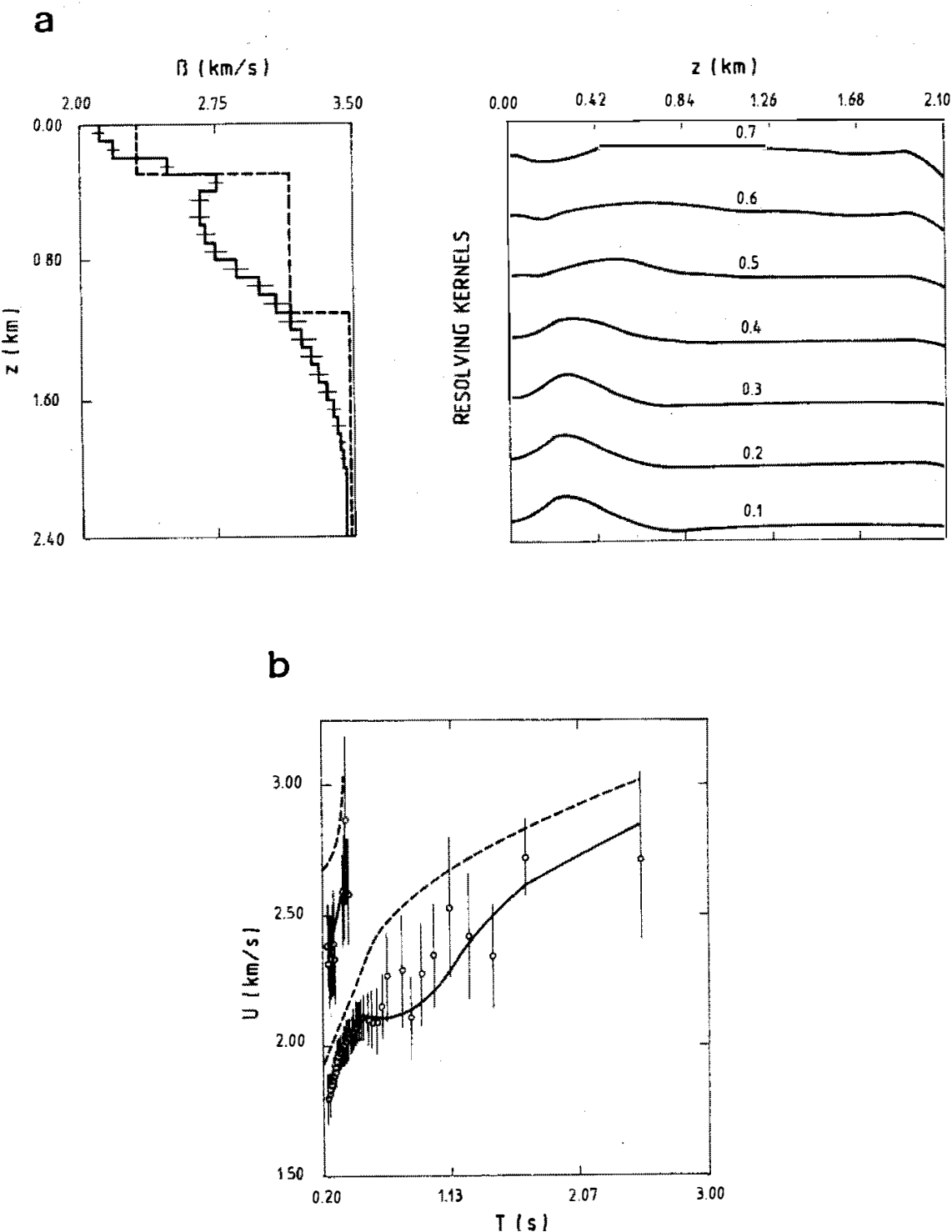

Fig. 9. (a) Shear velocity model corresponding to the first six traces of the SE side of the profile in Figure 1 , together with the resolving kernels calculated at several reference depths. Fundamental and first higher modes in Figure 6 have been used for inversion. The model with three layers indicates the starting model. (b) Observed (circles) and theoretical (solid lines) Rayleigh wave dispersion. Vertical bars indicate standard deviations. The dashed line indicates the theoretical group velocity determined from the shear starting model. 
profile includes Upper Precambrian and Lower Paleozoic areas and aluminous granites terrains. The SE side includes Upper Precambrian and Lower Paleozoic areas, aluminous granites terrains and the Vivero's fault. Although it is really difficult to relate the determined Rayleigh-wave velocities and the shear-wave velocity models to the geological structure of the region, it seems that the NW side, presenting a higher degree of heterogeneity, tends to slow the velocities more than the SE side. This fact seems to be in agreement with the general $P$ velocity model of Córdoba (1988), who found lower P velocities in the NW than in the SE side.

\section{Attenuation results}

Although determination of amplitude data in continental regions, and especially from seismic refraction profile records, is very hard to obtain and to analyze, we have calculated tentative attenuation coefficients for the regions under study and for a smaller period range than the one used in the velocity study. Attenuation data for periods greater than $1 \mathrm{~s}$ present to much scatter to be treated with confidence. Figures $10 \mathrm{a}$ and $11 \mathrm{a}$ show the determined attenuation coefficients, $\gamma$, for all the NW and SE traces, respectively. In general, $\gamma$-values decrease, from about $0.1-0.2$ $\mathrm{km}^{-1}$ at shorter periods (about $0.2 \mathrm{~s}$ ) to $0.02-0.05$ $\mathrm{km}^{-1}$ at larger periods (about $0.9 \mathrm{~s}$ ). The attenuation coefficients for both regions of this study present similar behavior, being somewhat higher in the northern than in the southern region. Determined standard deviations preclude us to infer any difference in anelasticity between both subregions. The low $\gamma$-values of the fundamental-mode Rayleigh-waves obtained in this region are consistent with the low $\gamma-L_{g}$-values obtained by García (1989) and Vives (1990) in different regions of the Iberian Peninsula. As far as we know, short-period attenuation studies using Rayleigh-waves have not been performed before in the Iberian Peninsula.

Figures $10 \mathrm{~b}$ and $11 \mathrm{~b}$ present tentative $Q_{\beta}^{-1}$ models corresponding to the NW and SE directions. Here, the obtained resolving kernels are, in both cases, similar to the ones associated to the

\section{a}
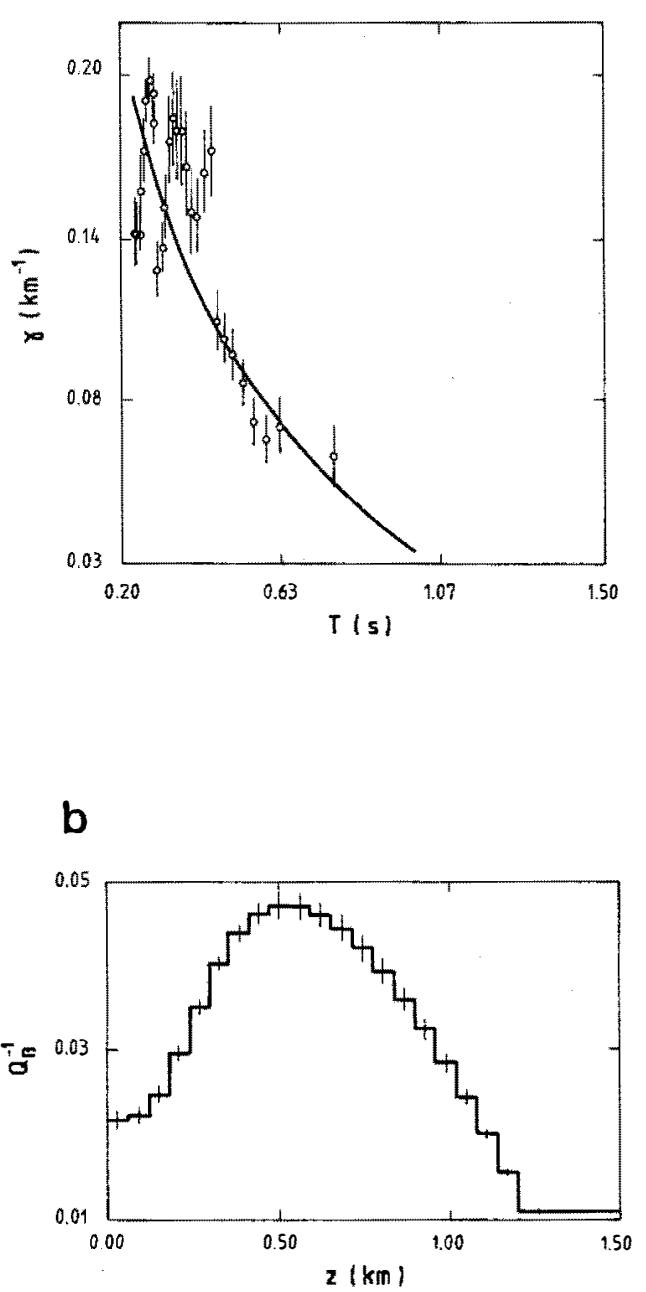

Fig. 10. (a) Observed attenuation coefficients (circles) of the Rayleigh-wave vertical component for the NW side, and theo retical ones (solid line) calculated from the model in Figure 10b. Vertical bars indicate standard deviations. (b) $Q_{\beta}^{-1}$ model determined from the attenuation data (circles) in (a). Starting model for the inversion procedure is $Q_{\beta}^{-1}=1$ (not shown).

shear-wave velocity models; therefore, they are not shown. Solid lines in Figures 10a and 11a present the adequate fit between the observed attenuation coefficients, mentioned in the last paragraph, and the theoretical ones generated by the models in Figures $10 \mathrm{~b}$ and $11 \mathrm{~b}$. Although qualitatively, both models are very similar, comparison between them indicates that the northern model seems to present lower $Q_{\beta}^{-1}$ values than the southern one. It seems also that the southern region presents a wider region with lower $Q_{\beta}$ 

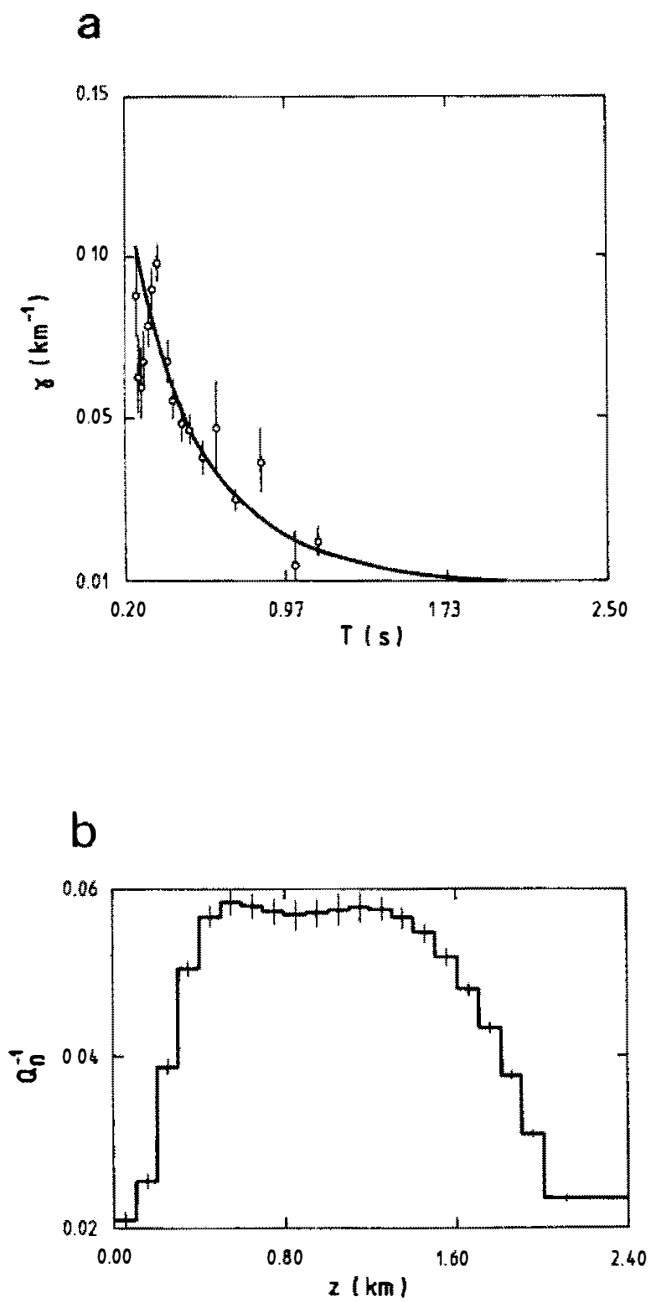

Fig. 11. (a) Observed attenuation coefficients (circles) of Rayleigh-wave vertical component for the SE side, and theoretical ones (solid line) calculated from the model in (b). Vertical bars indicate standard deviations. (b) $Q_{\beta}^{-1}$ model determined from the attenuation data (circles) in (a). Starting model for the inversion procedure is $Q_{\beta}^{-1}=1$ (not shown).

values than the northern one. Both $Q_{\beta}^{-1}$ models reach a maximum at about 0.05 . This value is located, in the NW model, between 0.4 and 0.6 $\mathrm{km}$ depth, and between 0.4 and $1.4 \mathrm{~km}$ in the SE one. As said before, it is well-known that attenuation studies in crustal regions (due to indeterminations in the amplitude data) are much more difficult than velocity studies. This reason precludes us to go further in the attenuation results and to infer any qualitative relation with the geological characteristics of the region. Much more attenuation data will be necessary to refine the obtained models.

\section{Conclusions}

Short-period surface-waves, from a seismic refraction profile line, have been used to determine shear velocity and $Q_{\beta}$ distributions in shallow parts of the crust in a region located in the northwestern Iberian Peninsula. The region under study has been divided into two subregions: one located to the NW side from the shot-point and the other one located to the SE side. Groupvelocity dispersion curves have been obtained for the two subregions and for the region covered by the first six traces in SE direction. The obtained fundamental-mode group-velocities for the $\mathrm{NE}$ region vary between $1.7 \mathrm{~km} \cdot \mathrm{s}^{-1}$ at about $0.2 \mathrm{~s}$ and $2.0 \mathrm{~km} \cdot \mathrm{s}^{-1}$ at about $0.9 \mathrm{~s}$. The $\mathrm{SE}$ region presents values ranging between $2.0 \mathrm{~km} \cdot \mathrm{s}^{-1}$ at about $0.2 \mathrm{~s}$, and $2.75 \mathrm{~km} \cdot \mathrm{s}^{-1}$ at about $2.5 \mathrm{~s}$. The region covered by the first six traces, in SE direction, presents group-velocity values varying between $1.8 \mathrm{~km} \cdot \mathrm{s}^{-1}$ at $0.2 \mathrm{~s}$ and $2.7 \mathrm{~km} \cdot \mathrm{s}^{-1}$ at about $2.5 \mathrm{~s}$. In this case it has also been possible to determine the group-velocity of the first higher mode up to periods about $0.4 \mathrm{~s}$. Velocities for the first higher-mode range between $2.35 \mathrm{~km} \cdot \mathrm{s}^{-1}$ at about $0.2 \mathrm{~s}$ and $2.85 \mathrm{~km} \cdot \mathrm{s}^{-1}$ at about $0.4 \mathrm{~s}$.

Inversion theory applied to the observed velocity data leads to the determination of shear-wave velocity models for the regions of this study. Shear velocities in the NW region seem to be somewhat lower than the corresponding ones for the SE region. Shear velocity varies in the NW region between $1.8 \mathrm{~km} \cdot \mathrm{s}^{-1}$ at the surface to 3.3 $\mathrm{km} \cdot \mathrm{s}^{-1}$ at about $1.2 \mathrm{~km}$ depth. In the SE region, the shear velocity varies between $2.2 \mathrm{~km} \cdot \mathrm{s}^{-1}$ at the surface and $3.4 \mathrm{~km} \cdot \mathrm{s}^{-1}$ at $1.2 \mathrm{~km}$ depth. It seems that lateral variations of $\mathrm{S}$ velocity may exist between both sides. Inverting only the first six traces in SE direction, the obtained shear velocity presents a small low-velocity channel located between 0.4 and $0.7 \mathrm{~km}$ depth. This fact may also indicate some lateral variation in the shear-wave velocity distribution in the SE region. More data is necessary to confirm the existence of this channel. 
The determined velocities seem to be related to the geological structures traversed by the waves. The northern side presents lower Rayleigh- and shear-wave velocities than the southern one. This fact may be due to a higher degree of heterogeneity in the northern part.

The attenuation coefficients for both regions are of the same order of magnitude. In general, $y$-values decrease, from $0.1-0.2 \mathrm{~km}^{1}$ at a period about $0.2 \mathrm{~s}$, to $0.02-0.05 \mathrm{~km}^{-1}$ at a period about $0.8 \mathrm{~s}$. The high attenuation coefficients obtained agree with the $\mathrm{L}_{\mathrm{g}}$ attenuation values obtained in several regions of the Iberian Peninsula. The tentative $Q_{\mathrm{s}}^{-1}$ models obtained from the attenuation data show similar maximum values (about 0.05). In the NW model, these values are obtained between 0.4 and $0.6 \mathrm{~km}$ depth; in the SE one, between 0.4 and $1.4 \mathrm{~km}$. Although these attenuation models must be treated as preliminary, they will serve as starting models when more and better data become available.

\section{Acknowledgements}

This research was supported by the Dirección General de Investigación Científica y Técnica (DGICYT) under grants PB87-0854 and PB890349. We thank Dr. Diego Córdoba, who provided the seismograms used in the analysis, and Dr. Robert B. Herrmann for helpful comments.

\section{References}

Anderson, D.L., Ben-Benahem, A. and Archambeau C.B., 1965. Attenuation of seismic energy in the upper mantle. J. Geophys. Res., 70: 1441-1448.

Badal, J., Corchete, V., Payo, G., Canas, J.A. and Pujades, L. and F. Serón, 1990. Processing and inversion of long-period surface-wave data collected in the Iberian Peninsula. Geophys. J. Int., 100: 193-202.

Barker, T.G., 1988. Array processing of Rayleigh waves for shallow shear wave velocity structure (Abstr.). Seismol. Res. Lett., 59: 12.

Canas, J.A., Miguel, F. and Vidal, F., 1988. Anelastic Rayleigh wave attenuation in the Iberian Peninsula. Geophys. J.R. Astron. Soc., 95: 391-396.

Córdoba, D., 1988, Estudio de la Litosfera en el Noroeste de la Peninsula Ibérica. Desarrollo de un Sistema de Digitalización y Procesado de Señales. Ph.D. Thesis, Univ. Complutense Madrid, Madrid, 292 pp.

Córdoba, D., Banda, E. and Ansorge, J., 1987. The Hercynian crust in northwestern Spain: a seismic survey. Tectonophysics, 132: 321-333.

Dziewonski, A.M., Bloch, S. and Landisman, M., 1969. A technique for the analysis of tranient seismic signals. Bull Seismol. Soc. Am., 59: 427-444.

Fuchs, K and Müller, G., 1971. Computation of synthetic seismograms with the reflectivity method and comparison with observations. Geophys. J.R. Astron. Soc., 23: 417433.

García, M., 1989. Atenuación espectral de ondas $L_{g}$ y pseudoaceleración máxima del terreno en la Península Ibérica. Ph.D. Thesis, Univ. Politécnica Catalunya, Barcelona, 233 pp.

Herrmann R.B., 1973. Some aspects of band-pass filtering of surface waves. Bull Seismol. Soc. Am., 63: 663-671.

Macbeth, C.D. and Burton, P.W., 1986. Propagation of 0.7-2.5 $\mathrm{Hz}$ Rayleigh waves in Scotland. Geophys. J.R. Astron. Soc., 84: 101-120.

Matte, Ph., 1983. Two geotraverses across the Ibero-Armorican Variscan arc of western Europe. In: N. Rast and F.M. Delany (Editors), Profiles of Orogenic Belts. Am. Geophys. Union, Washington, DC/Geol. Soc. Am., Boulder, CO, pp. 53-81.

Menke, W., 1989. Geophysical Data Analysis: Discret Inverse Theory. Academic Press, New York, NY, 289 pp.

Mitchell, B.J., 1975. Regional Rayleigh wave attenuation in North America. J. Geophys. Res., 80: 4904-4916.

Mitchell, B.J., 1976. Anelasticity of the crust and upper mantle beneath the Pacific Ocean from the inversion of observed surface wave attenuation. Geophys. J.R. Astron. Soc., 46: 521534.

Mokhtar, T.A., Herrmann R.B. and Russell D.R., 1988. Seis mic velocity and $Q$ model for the shallow structure of the Arabian shield from short-period Rayleigh waves. Geophysics, 53: 1379-1387.

Rodi, W.L., Glover, P., Li, M.C. and Alexander S.S., 1975. A fast, accurate method for computing group-velocity partial derivatives for Rayleigh and Love modes. Bull Seismol. Soc. Am., 65: 1105-1114.

Russell, D.R., 1987. Multi Channel Processing of Dispersed Surface Waves. Ph.D. Thesis, St. Louis Univ., St. Louis.

Twomey, S., 1977. Introduction to the Mathematics of Inversion in Remote Sensing and Indirect Measurements. Elsevier, Amsterdam, 243 pp.

Vives, V., 1990. Parámetros sísmicos de interes ingenieril en el Noreste y Levante de la Península Ibérica. Aplicación a la zona de Ascó. Ph.D. Thesis, Univ. Politécnica Catalunya, Barcelona, 346 pp.

Wiggins, R.A., 1972. The general linear inverse problems, implication of surface waves and free oscillation for earth structure. Rev. Geophys. Space Phys., 10: 251-285. 